\title{
Quantifying the distribution of critical metals in conventional passenger vehicles using input-driven and output-driven approaches: a comparative study
}

\author{
Xiaoyue Du • Eliette Restrepo • Rolf Widmer • \\ Patrick Wäger
}

Received: 5 May 2014/Accepted: 9 January 2015/Published online: 21 January 2015

(C) Springer Japan 2015

\begin{abstract}
Critical metals are used increasingly in vehicle manufacturing. For more sustainable use of these metals, it is important to understand their distribution in vehicles. In this paper, we present a comparative study examining the distribution of critical metals in conventional passenger vehicles. We identified two existing approaches to estimate the amounts of critical metals used in one passenger vehicle: input-driven and output-driven approach, and compared the results of 25 metals among five studies. In general, the results were found to be scattered. $\mathrm{Cu}, \mathrm{Mn}, \mathrm{Sr}$ and $\mathrm{Sb}$ were found with the highest median masses per vehicle. The median masses of eight metals ( $\mathrm{Nb}, \mathrm{Zr}$, Co, $\mathrm{La}, \mathrm{Mo}, \mathrm{Nd}, \mathrm{Ce}$, and $\mathrm{Ag}$ in descending order) were around or below $10 \mathrm{~g}$ per vehicle and those of 13 metals $(\mathrm{Pd}, \mathrm{Ta}$, $\mathrm{Pr}, \mathrm{Ga}, \mathrm{Sm}, \mathrm{Y}, \mathrm{W}, \mathrm{Au}, \mathrm{Gd}$, Dy, In, Pt, and Tb in descending order) were below $1 \mathrm{~g}$ per vehicle. Top three subsystems and parts containing the largest mass of critical metals in sum were presented. Our research provides a consolidated summary of existing information on the critical metal distribution in conventional passenger vehicles and suggests improvements for future studies on this topic.
\end{abstract}

Keywords Critical metals - Conventional passenger vehicles · End of life vehicles (ELV) .

Rare earth elements (REE)

Electronic supplementary material The online version of this article (doi:10.1007/s10163-015-0353-3) contains supplementary material, which is available to authorized users.

X. Du $(\bowtie) \cdot$ E. Restrepo · R. Widmer · P. Wäger

Empa, Swiss Federal Laboratory for Materials Science and Technology, Lerchenfeldstrasse 5, 9014 St. Gallen, Switzerland e-mail: xiaoyue.du@empa.ch

\section{Introduction}

As the technology advances, an increasing number of metals are used in the production of conventional passenger vehicles due to their unique physical and chemical properties. For example, neodymium is used in high-performance $\mathrm{NdFeB}$ permanent magnets in the motors [1-3], and indium is essential in liquid crystal displays for Global Positioning System (GPS) [4]. Many of the metals used in vehicles are considered critical in terms of high supply risks and high impact from a potential supply disruption. Among others, this is the case for cobalt (Co), gallium $(\mathrm{Ga})$, indium $(\mathrm{In})$, niobium $(\mathrm{Nb})$, platinum group metals (PGM), rare earth elements (REE), antimony (Sb), tantalum (Ta), and tungsten (W) [5-7]. As the demand of critical metals soars, it requires a more sustainable life cycle management of these metals [8]. Regarding end of life management, it is fundamental to know the distribution of critical metals in vehicles: where and how much of a critical metal is in a vehicle. While many studies have investigated metals such as iron, aluminum and lead in both passenger vehicle parts and end of life vehicle (ELV) shredder outputs [9], the information remains scarce and scattered for critical metals, particularly for those used in small amounts in the vehicles.

In our study, we aim to provide the most recent and comprehensive information on the distribution of critical metals in conventional passenger vehicles by compiling and comparing scattered information. For this purpose, we draw upon five studies from Japan, Sweden, Switzerland and the US [10-14] and focus on 25 metals. We present the distribution by providing the masses of individual critical metals per vehicle among the five studies and by identifying hot spots. We identify reasons for the scattered results among the five studies, address the advantages and limitations of 
methodologies, and give suggestions on how to improve the assessment of the critical metals in passenger vehicles. Overall, our research provides a consolidated and most upto-date summary of existing information on critical metal distribution in conventional passenger vehicles.

\section{Methodology}

In this comparative study, we drew upon five studies [1014], which according to our knowledge are the only ones to have addressed "critical", "scarce" or "rare" metals or elements (including metals and non-metals) in conventional passenger vehicles or ELV shredder output fractions. The five studies were conducted by a variety of groups including government, automobile industry, recycling industry and research institution.

First, the five studies were reviewed regarding the purpose, scope, methodology and results. Two studies were published in Japanese so translation was done when needed $[10,11]$. The authors of the studies were contacted when further information for the comparison was needed. Two approaches of quantifying the metal distribution in conventional passenger vehicles were identified among the five studies.

Second, we identified and selected the metals being investigated in at least three studies of the five studies as the focus in our comparison because it allows a broader scope for more comprehensive conclusions. These 25 metals are: silver $(\mathrm{Ag})$, gold $(\mathrm{Au})$, cerium $(\mathrm{Ce})$, cobalt $(\mathrm{Co})$, copper $(\mathrm{Cu})$, dysprosium (Dy), gallium $(\mathrm{Ga})$, gadolinium ( $\mathrm{Gd}$ ), indium (In), lanthanum (La), manganese $(\mathrm{Mn})$, molybdenum (Mo), niobium $(\mathrm{Nb})$, neodymium $(\mathrm{Nd})$, palladium $(\mathrm{Pd})$, praseodymium $(\mathrm{Pr})$, platinum $(\mathrm{Pt})$, antimony $(\mathrm{Sb})$, samarium $(\mathrm{Sm})$, strontium $(\mathrm{Sr})$, tantalum $(\mathrm{Ta})$, terbium (Tb), tungsten (W), yttrium (Y) and zirconium $(\mathrm{Zr})$. All the 25 metals have been considered critical in previous criticality studies $[5-7,15,16]$.

Third, we presented the masses of individual metals per vehicle from each study and identified the median values for each metal among these five studies. We identified three subsystems in the individual studies as "hot spots" which contain in one vehicle the largest total mass of all critical metals considered.

Finally, we discuss the possible reasons for the dispersed results from the five studies, address the benefits and limitations of the two approaches and suggest how to improve the study of critical metal distribution in passenger vehicles in future.

\section{Results}

The five studies we reviewed answered different questions regarding "critical", "scarce", or "rare" metals or elements (including metals and non-metals) in conventional passenger vehicles. All studies were carried out after 2009. Table 1 summarizes the purpose, scope, methodologies and results of the five studies.

By reviewing the five studies, we derived a generic definition of a conventional passenger vehicle as an internal combustion engine (ICE) vehicle (using either diesel or gasoline), with a mass between 1000 and $2000 \mathrm{~kg}$ and a capacity to carry four to five people. A conventional passenger vehicle is built with subsystems, which are made from assembled parts working together to accomplish the vital functions in the vehicle. The parts contain a number of components and some components may need to be further divided. Thus, the vehicle is modeled as a hierarchical assembly of subsystems, parts and components. The same parts and component may occur in several subsystems and parts, respectively. As an example, a subsystem called "steering" includes, amongst other parts, a servomotor, a controller and a steering column. The servomotor contains, amongst other components, magnets, a commutator and electric brushes. Magnets also exist in many other parts such as wipers, starter motors and loudspeakers. A component such as a printed circuit board (PCB) is composed of electronic items such as resistors, capacitors and integrated circuits all mounted on the PCB and mostly contain critical metals. In our comparison, we limited the hierarchy to three levels: subsystems, parts and components.

Among the five studies, we identified two approaches of determining the mass of metals in a vehicle and we call these two approaches input-driven approach and outputdriven approach [17].

In an input-driven approach, the metal content of individual components (or parts) of the vehicle is examined. The total mass of a metal in a vehicle is calculated by aggregating the metal's masses in all the components in all the parts included in one vehicle. The aggregation can be done using either collected data or measured data. Collected data refer to the data gathered by surveying part suppliers, or using existing database of the vehicle manufacturer, or by any other similar activities. Measured data refer to the data obtained in an experiment through measurement of the components and parts from the vehicles. The following Eq. 1 serves as a generalization of the inputdriven approach:

$M_{x}=\sum_{j=1}^{\mathrm{G}} \sum_{i=1}^{\mathrm{K}} C_{x i} \times M_{i j}$

where $M_{x}$ is the mass of metal $x$ in a conventional passenger vehicle, $C_{x i}$ is the concentration of metal $x$ in component $i$ and $M_{i j}$ is the mass of component $i$ in part $j$. $G$ is the total number of the parts considered and $K$ is the total number of the components considered. 
Table 1 Summary of purpose, scope, methodologies and results of the five studies

\begin{tabular}{|c|c|c|c|c|c|c|c|}
\hline \multirow{2}{*}{\multicolumn{2}{|c|}{ Study }} & Switzerland & US & Sweden & Japan & Switzerland & Japan \\
\hline & & Widmer et al. [14] & Alonso et al. [13] & Cullbrand and Magnusson [12] & MOE [11] & Widmer et al. [14] & MOE [10] \\
\hline \multicolumn{2}{|l|}{ Purpose } & $\begin{array}{l}\text { To gain an overview } \\
\text { on the distribution of } \\
\text { scarce metals in } \\
\text { electrical and } \\
\text { electronic } \\
\text { components in } \\
\text { conventional } \\
\text { passenger vehicles }\end{array}$ & $\begin{array}{l}\text { To place estimates of the } \\
\text { future demand for REE in } \\
\text { the automotive industry by } \\
\text { means of a detailed } \\
\text { assessment of the REE } \\
\text { content of conventional } \\
\text { and electric vehicles }\end{array}$ & $\begin{array}{l}\text { To provide knowledge on the use } \\
\text { of potentially critical materials } \\
\text { in passenger cars }\end{array}$ & $\begin{array}{l}\text { To identify the amount of } \\
\text { hazardous metals and other } \\
\text { critical metals in conventional } \\
\text { and hybrid vehicles to assess } \\
\text { how new designs reflect in the } \\
\text { amount of hazardous metals and } \\
\text { critical metals used }\end{array}$ & $\begin{array}{l}\text { To analyze the distribution } \\
\text { of scarce metals in ELV } \\
\text { shredder outputs to } \\
\text { formulate strategies to } \\
\text { improve the pretreatment } \\
\text { of ELV, regarding } \\
\text { recovery of scarce metals }\end{array}$ & $\begin{array}{l}\text { To evaluate how } \\
\text { changes in vehicle } \\
\text { design reflect in the } \\
\text { composition of } \\
\text { ELV shredder } \\
\text { fractions, regarding } \\
\text { selected elements }\end{array}$ \\
\hline \multirow[t]{7}{*}{ Scope } & $\begin{array}{l}\text { Vehicle } \\
\text { considered }\end{array}$ & $\begin{array}{l}\text { Conventional } \\
\text { passenger vehicle }\end{array}$ & $\begin{array}{l}\text { Hypothetical North America } \\
\text { conventional midsize } \\
\text { sedan, Hypothetical North } \\
\text { America hybrid vehicle }\end{array}$ & $\begin{array}{l}\text { Volvo conventional midsize low } \\
\text { specified vehicle (CML), } \\
\text { Conventional midsize high } \\
\text { specified (CMH), conventional } \\
\text { large medium specified } \\
\text { (CLM), hybrid midsize } \\
\text { medium specified (HMM) }\end{array}$ & Toyota Crown, Toyota Pirus & $\begin{array}{l}7 \text { shredder output fractions } \\
\text { from a batch test of } 100 \\
\text { randomly selected ELV }\end{array}$ & $\begin{array}{l}\text { Mixed shredder } \\
\text { output except the } \\
\text { iron fraction }\end{array}$ \\
\hline & Year & $\begin{array}{l}\text { Manufactured between } \\
2005 \text { and } 2008\end{array}$ & 2012 model & $\begin{array}{l}\text { "Being produced currently or in } \\
\text { the near future" (study was } \\
\text { published in 2011) }\end{array}$ & 2002 model & $\begin{array}{l}\text { Manufactured between } 2000 \\
\text { and } 2010\end{array}$ & $\begin{array}{l}70 \text { ELV } \\
\text { manufactured } \\
\text { before 1996, } 70 \\
\text { ELV manufactured } \\
\text { after } 2000\end{array}$ \\
\hline & Weight & Not provided & Not provided & $\begin{array}{l}\text { CML: } 1500-1700 \mathrm{~kg}, \mathrm{CMH}: \\
\text { 1500-1800 kg, CLM: } \\
\text { 1800-2200 kg, HMM: } \\
\text { 1900-2100 kg }\end{array}$ & Not provided & Not provided & $\begin{array}{l}\text { ELV b1996: } \\
600-1700 \mathrm{~kg} \\
\text { ELV a2000: } \\
600-1700 \mathrm{~kg}\end{array}$ \\
\hline & $\begin{array}{l}\text { Subsystem } \\
\text { or groups }\end{array}$ & 6 functional groups & 13 subsystems & 31 subsystems & 4 groups & Not applicable & Not applicable \\
\hline & $\begin{array}{l}\text { Parts } \\
\text { considered }\end{array}$ & $\begin{array}{l}119 \text { parts selected } \\
\text { containing electrical } \\
\text { and electronic } \\
\text { components }\end{array}$ & $\begin{array}{l}76 \text { parts selected to represent } \\
\text { conventional vehicle } \\
\text { (>700 parts reported) }\end{array}$ & $\begin{array}{l}482 \text { parts containing the metals } \\
\text { out of a total of } 1552 \text { parts }\end{array}$ & 92 parts (shown in results) & Not applicable & Not applicable \\
\hline & Components & $\begin{array}{l}17 \text { electrical and } \\
\text { electronic } \\
\text { components }\end{array}$ & Not considered & Not considered & Not considered & Not applicable & Not applicable \\
\hline & Coverage & $\begin{array}{l}31 \text { scarce metals, } \\
\text { including } 9 \text { REE }\end{array}$ & $\begin{array}{l}\text { REE ( } 12 \text { REE shown in } \\
\text { results) }\end{array}$ & $\begin{array}{l}31 \text { potentially critical materials } \\
\text { (all metals), including } 12 \text { REE }\end{array}$ & 24 elements, including 4 REE & $\begin{array}{l}31 \text { scarce metals, including } \\
9 \text { REE }\end{array}$ & $\begin{array}{l}42 \text { elements, } \\
\text { including } 4 \text { REE }\end{array}$ \\
\hline \multirow[t]{2}{*}{ Methodology } & Approach & Input-driven & Input-driven & Input-driven & Input-driven & Output-driven & Output-driven \\
\hline & $\begin{array}{l}\text { Data } \\
\text { acquisition }\end{array}$ & Measured data & Collected data & Collected data & Measured data & Measured data & Measured data \\
\hline Results & & $\begin{array}{l}\text { Numeric values (mass } \\
\text { and concentration) }\end{array}$ & Numeric values (mass) & $\begin{array}{l}\text { Numeric values (mass for } 20 \\
\text { metals), graphic presentation } \\
\text { (mass for } 7 \text { metals) }\end{array}$ & Numeric values (mass) & $\begin{array}{l}\text { Numeric values (mass and } \\
\text { concentration) }\end{array}$ & $\begin{array}{l}\text { Numeric values } \\
\text { (concentration) }\end{array}$ \\
\hline
\end{tabular}

Widmer et al. [14] studied the vehicle components and shredder outputs independently so it was listed twice to present the input-driven and output-driven approach separately 
In an output-driven approach, the metal content of individual shredder output fractions is examined. The shredder output fractions refer to the material output at an ELV shredder. ELV are usually dismantled according to the local legislative system before entering the shredder. At the shredder, ELV undergo a series of physical treatments, including shredding and several steps of separation. As a result of physical treatment, several shredder output fractions are generated at the shredder. The shredder output fractions can vary due to the different processes at different shredders. The total mass of a metal in a vehicle is calculated by aggregating the metal's masses in all the shredder output fractions and dividing by the number of vehicles shredded in the batch test. The aggregation is done normally by using measured data. Measured data refer to the data obtained in an experiment through the measurement of the shredder output fractions sampled from a batch test. The following Eq. 2 serves as a generalization of the output-driven approach:

$M_{x}=\frac{1}{N_{\mathrm{b}}} \sum_{j=1}^{\mathrm{F}} C_{x j} \times M_{j}$

where $M_{j}$ is the mass of shredder output fraction $j ; C_{x j}$ is the concentration of metal $x$ in fraction $j ; N_{\mathrm{b}}$ is the number of vehicles shredded in the batch test; and $F$ is the total number of shredder output fractions considered. All the five studies we compared followed either input-driven approach or output-driven approach as we summarized above. Three of the five studies [11-13] have applied inputdriven approach to determine the mass of individual metals in one conventional passenger vehicle. Two studies [12, 13] used collected data and the other one [11] used measured data. One study [10] has applied output-driven approach to determine the concentration of individual metals in shredder output fractions and it used measured data. One study [14] has applied both input-driven approach and output-driven approach using measured data.

Alonso et al. [13] assessed the REE content in a 2012 model "hypothetical conventional gasoline engine North American midsize sedan" and "a hypothetical full hybrid sedan with a lithium battery". This study has applied inputdriven approach. To estimate the REE content, Alonso et al. used data reported from vehicle part suppliers (collected data). The authors identified parts containing REE from over 700 reported parts and categorized the parts into 13 subsystems which were defined based on the advice from expert in auto industry. Examples of the subsystems are "engine", "fuel and exhaust", and "information and controls". The authors selected "representative parts" to construct a hypothetical vehicle "based on the criteria that the part was used in a midsize sedan and contained an average rare earth quantity relative to the other reported midsize sedan parts".
The authors calculated the individual REE content in a vehicle by aggregating the individual REE in all the selected parts. The total mass of all 12 REE and individual mass of 12 REE were presented in results. The distribution of the total mass of all 12 REE among the subsystems was also presented. For our comparative study, the results of the "hypothetical conventional gasoline engine North American midsize sedan" were used.

Cullbrand and Magnusson [12] mapped the use of " 31 potentially critical materials" (which are all elemental metals) in four different vehicles: Conventional Midsize Car, Low Specified (CML); Conventional Midsize Car, High Specified (CMH); Conventional Large Car, Medium Specified (CLM) and Hybrid Midsize Car, Medium Specified (HMM). This study has applied input-driven approach. The authors described the models and configurations in general as "four different car configurations of three different Volvo car models" and then provided more details including weight, number of parts, and a list of standard equipment. The manufacturing year or model year was described as "being produced currently or in the near future" (study was published in 2011). To estimate the metal content in one vehicle, the authors used data from the International Material Data System (IMDS) "containing hundreds of thousands reported data sheets of car parts" (collected data). The authors performed a search in the IMDS for the parts containing the investigated metals and matched the parts with the specification of each car. Not all the parts in four models were reported in the database. For the non-reported parts which were still considered of interest in the study, the suppliers were contacted to provide the material content in the part or in a similar part. 31 subsystems were defined and the parts were allocated to the subsystems according to "the Volvo Car Corporation notation of vehicle subsystems". The authors calculated the total metal content in one car by aggregating the metal masses in all the selected parts. Due to the limitation of the software used to access the IMDS, detailed analysis was not done for seven of the 31 metals. Only the total mass for each metal was calculated from the reported parts. The study presented the masses of 20 individual metals in one vehicle in numeric values. The results including the masses of 20 individual metals by subsystems in numeric values and the masses of seven other metals in one vehicle which were in graphic presentation and no numeric values were provided. For our comparative study, the results of 27 metals in CML model were used and the mass for seven out of the 27 metals had to be estimated from the charts. We chose to use the results of CML model because the definition of CML model is the closest to the generic definition of conventional passenger vehicle we derived from reviewing the five studies. 
MOE [11] studied the content of 24 elements (including 22 metals and the two metalloids As and Sb) in two different vehicles: 2002 Toyota Crown and 2002 Toyota Pirus. The authors dismantled the vehicles and acquired 92 parts to be investigated in the study and then carried out chemical analysis to measure the metal concentration in individual part. The authors divided the 92 parts into four groups: exterior, interior, functional mechanical and body. The results were presented as masses of individual elements in individual part and the total masses of individual elements in one vehicle for both two vehicles. For our comparative study, the results of 2002 Toyota Crown were used.

MOE [10] studied the composition of selected shredder output fractions with particular interest to "grasp how the efforts in the design and manufacturing phases exert influence on the composition of automotive shredder residue". To identify and analyze the characteristics of automobile shredder residue (ASR), the authors acquired 70 ELV manufactured before 1996 (ELV b1996) and 70 ELV manufactured after 2000 (ELV a2000). "Only city cars and standardsized passenger cars" were considered and the authors "took models and displacement into consideration when choosing cars". The authors provided information of all the vehicles including make, model, weight, engine displacement, and manufacturing year. First some parts were removed and a list of those was provided. Then, ELV were disassembled according to the standard procedure of auto dismantlers and then were shredded by specialist shredders. Thus, ASR from ELV b1996 and from ELV a2000 was collected and sampled at the designated collection site in the ASR recycling facility. To quantify the composition of ASR, the author sampled five output fractions (except the iron fraction) and carried out chemical analysis to measure the element concentration in the mixture of five fractions (measured data) for both ELV b1996 and ELV a2000. The study presented metal concentrations for 42 elements in the mixture of five fractions. For our comparative study, the results of both ELV b1996 and ELV a2000 were used and the metal concentrations were calculated to masses using Eq. 2.

Widmer et al. [14] investigated 31 "scarce metals" in the electrical and electronic (EE) components in conventional passenger vehicles and in the shredder output fractions of ELV. This study has applied both approaches to quantify the distribution of 31 scarce metals in conventional passenger vehicles. In the input-driven approach, 119 parts containing EE components were provided by a Swiss spare part dealer. These parts were categorized into six groups based on their functionality. All the parts were from the vehicles manufactured between 2005 and 2008 and each part was documented with details such as model, year and weight. The 119 parts were manually dismantled to obtain 17 types of components. To quantify the metal content, these 17 types of components were chemically analyzed to acquire the metal concentration (measured data) and the masses of the individual metals in one hypothetical vehicle were calculated. In the output-driven approach, 100 ELV manufactured between 2000 and 2010 were randomly selected and went through a batch test at a shredder in Switzerland. The authors sampled the seven output fractions and conducted chemical analysis to measure each fraction individually to obtain the metal concentrations (measured data). The authors derived the results of masses of individual metals in one vehicle by aggregating the metal masses in EE components and shredder output fractions. This study presented the masses of the 31 metals in the EE components in one vehicle and the masses of the 31 metals in 100 ELV. For our comparative study, both sets of results were used.

A total of 57 elements were addressed in the five studies; 49 of them were metals and the remaining eight were metalloids (B, Si, Ge, As, Se, Br, Sb, and Te). Three of the metalloids ( $\mathrm{Ge}, \mathrm{Sb}$, and $\mathrm{Te}$ ) were considered as metals by Widmer et al. [14], because of their major applications as metal alloys in electronics [18-20]. These three metalloids are also considered as metals in this study. Alonso et al. [13] did not explicitly address the number of REE they considered and 12 REE were assumed as the focus of their study as they presented the results for 12 REE. Table 2 shows the elements and their occurrence in the five studies.

A total of 25 different metals were analyzed by at least three studies (first three rows of Table 2). Among these 25 metals, the studies agree that $\mathrm{Cu}$ and $\mathrm{Mn}$ were found with the highest median masses in the vehicles compared to the other metals. $\mathrm{Cu}$ was found with the median mass at $3.38 \mathrm{~kg}$ per vehicle and $\mathrm{Mn}$ at $2.53 \mathrm{~kg}$ per vehicle. Both $\mathrm{Cu}$ and $\mathrm{Mn}$ have been investigated in three studies [10-12] (MOE [10]

Table 2 The occurrence of the 57 elements in the five studies

\begin{tabular}{llr}
\hline No. of studies & Elements & No. of elements \\
\hline 5 & $\mathrm{Dy}, \mathrm{Nd}, \mathrm{Sm}$ & 3 \\
4 & $\mathrm{Co}, \mathrm{Ga}, \mathrm{In}, \mathrm{La}, \mathrm{Mo}, \mathrm{Nb}, \mathrm{Pd}, \mathrm{Pt}, \mathrm{Ta}, \mathrm{Tb}$ & 10 \\
3 & $\mathrm{Ag}, \mathrm{Au}, \mathrm{Ce}, \mathrm{Cu}, \mathrm{Gd}, \mathrm{Mn}, \mathrm{Pr}, \mathrm{Sb}, \mathrm{Sr}, \mathrm{W}, \mathrm{Y}, \mathrm{Zr}$ & 12 \\
2 & $\mathrm{As}, \mathrm{Cr}, \mathrm{Eu}, \mathrm{Ge}, \mathrm{Li}, \mathrm{Mg}, \mathrm{Ni}, \mathrm{Pb}, \mathrm{Rh}, \mathrm{Sn}, \mathrm{Hg}, \mathrm{V}, \mathrm{Yb}$ & 13 \\
1 & $\mathrm{Al}, \mathrm{B}, \mathrm{Ba}, \mathrm{Be}, \mathrm{Br}, \mathrm{Ca}, \mathrm{Cd}, \mathrm{Er}, \mathrm{K}, \mathrm{Na}, \mathrm{Rb}, \mathrm{Re}, \mathrm{Ru}, \mathrm{Sc}, \mathrm{Se}, \mathrm{Si}, \mathrm{Te}, \mathrm{Ti}, \mathrm{Zn}$ & 19 \\
\hline
\end{tabular}


presented two sets of results for ELV b1996 and ELV a2000). The mass of $\mathrm{Cu}$ per vehicle ranged from 2.3 to $3.8 \mathrm{~kg}$ in two studies [10,11] and amounted to $25 \mathrm{~kg}$ in Cullbrand and Magnusson [12]. The mass of Mn was around $20 \mathrm{~g}$ in MOE [10] while between 5 and $6 \mathrm{~kg}$ per vehicle in the other two studies [11, 12]. Figure 1 shows the individual and median masses of the remaining 23 metals in one conventional passenger vehicle from the five studies.

Except $\mathrm{Cu}$ and $\mathrm{Mn}$, most metals were found in small amounts. $\mathrm{Sr}$ and $\mathrm{Sb}$ were found with the higher median masses than the rest at 142.67 and $46.39 \mathrm{~g}$ per vehicle. The median masses of eight metals $(\mathrm{Nb}, \mathrm{Zr}, \mathrm{Co}, \mathrm{La}, \mathrm{Mo}, \mathrm{Nd}$, $\mathrm{Ce}$, and $\mathrm{Ag}$ in descending order) were around or below 10 g per vehicle. 13 metals (Pd, Ta, Pr, Ga, Sm, Y, W, Au, $\mathrm{Gd}$, Dy, In, Pt, and $\mathrm{Tb}$ in descending order) were found with the median mass below $1 \mathrm{~g}$ per vehicle. Except the median mass of $0.93 \mathrm{~g}$ Pd per vehicles, the rest group was found with the median mass around and less than $0.5 \mathrm{~g}$ per vehicle. $\mathrm{Pd}$ and $\mathrm{Tb}$ had the lowest median masses which were less than $0.01 \mathrm{~g}$ per vehicle.

The results of the five studies are scattered for most metals. For example, the mass of Ce ranged from 0.02 to $81 \mathrm{~g}$ per vehicle among the four studies where Ce was considered. Dy was found below $1 \mathrm{~g}$ per vehicle in most of studies except being $27.45 \mathrm{~g}$ in Alonso et al. [13].

Alonso et al. [13] showed higher results for most metals compared to other studies, while Widmer et al. [14] showed smaller results in the input-driven approach than others. Among the 25 metals considered in this comparative study, nine metals were found in Alonso et al. [13] and seven of these nine metals (which are Ce, Dy, Gd, Nd, Pr, $\mathrm{Sm}$ and $\mathrm{Y}$, except $\mathrm{La}$ and $\mathrm{Tb}$ ) were presented with largest mass in Alonso et al. [13]. The smallest masses for 15 metals were found in the results from input-driven approach in Widmer et al. [14].

The REE are a group of 16 elements including 14 lanthanides, $\mathrm{Y}$ and $\mathrm{Sc}$ (Pm is radioactive so it is not included). They were of particular interest among the five studies. A total of 13 REE have been studied by the five studies and 9 REE have been studied by at least three studies. Table 3 shows the results of 13 REE in comparison.

Most studies agreed on $\mathrm{Nd}$ and La being the two metals with the largest mass among the REE in conventional passenger vehicles [11-14]. However, both metals were presented with a wide range of results among the five studies. $\mathrm{Nd}$ ranged from 1.31 to $297 \mathrm{~g}$ and $\mathrm{La}$ ranged from 0.84 to $12 \mathrm{~g}$ per vehicle among the five studies. The rest of the REE were found in much smaller amounts, typically below $1 \mathrm{~g}$ per vehicle. The mass of $\mathrm{Tb}$ was the smallest (around or less than $0.01 \mathrm{~g}$ per vehicle) among all REE as shown in four
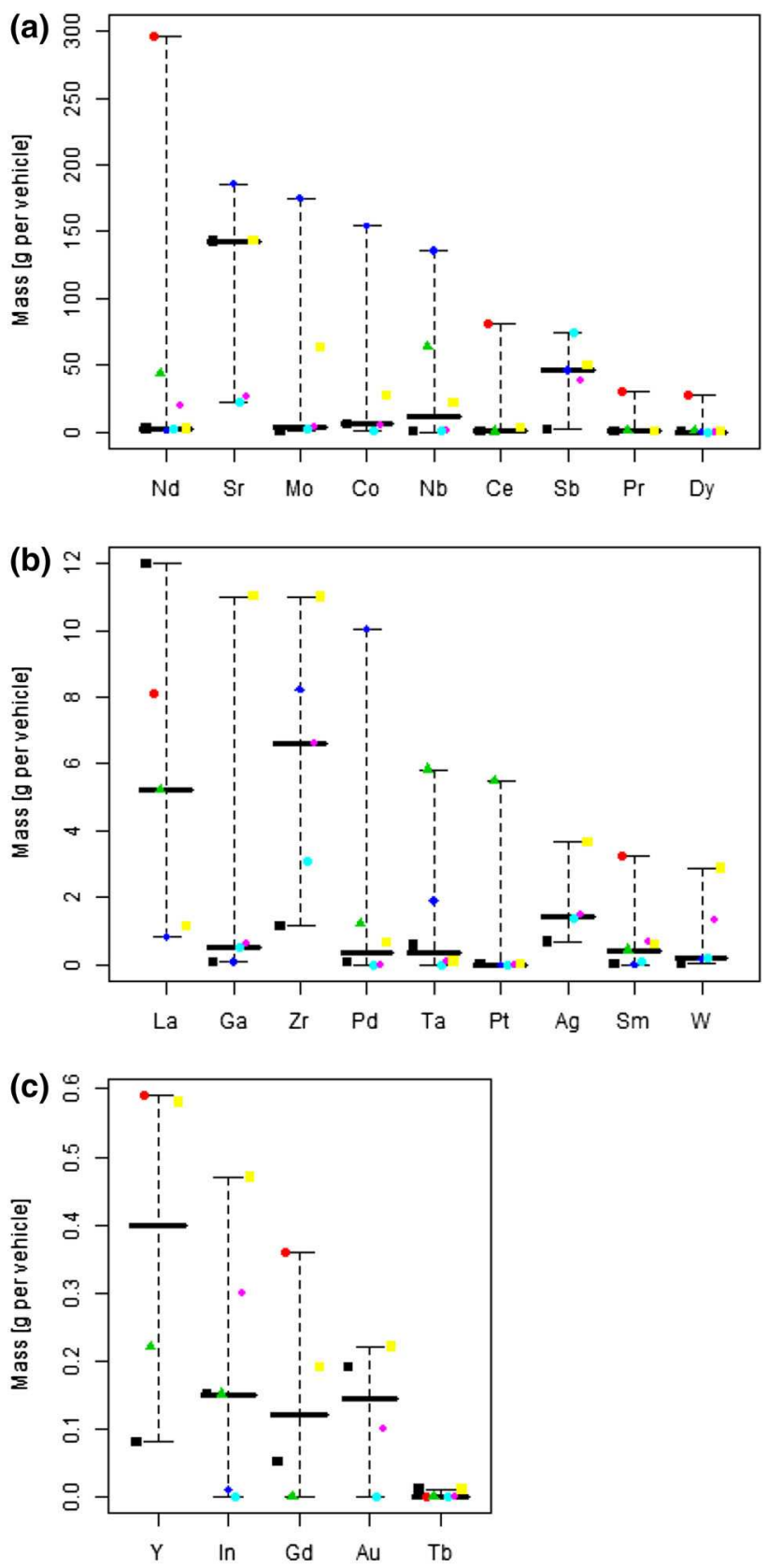

- Widmer et al., 2014 [14], input-driven

- Alonso et al., 2012 [13], input-driven

- Cullbrand et al., 2011 [12], input-driven

- MOE, 2009 [11], input-driven

- MOE, 2010 [10], output-driven, b1996

- MOE, 2010 [10], output-driven, a2000

Widmer et al., 2014 [14], output-driven

Fig. 1 a-c The mass of 23 metals (except $\mathrm{Cu}$ and $\mathrm{Mn}$ ) in one conventional passenger vehicle (g per vehicle). The results of masses from the five reviewed studies are shown as the individual data points in different markers. The thick black bars are the medians of the results from the five studies. The upper and lower whiskers indicate the maximum and minimum masses from the five studies 
Table 3 The mass of 13 REE in one conventional passenger vehicle among five studies (g per vehicle)

\begin{tabular}{|c|c|c|c|c|c|c|c|}
\hline \multirow[t]{2}{*}{ REE } & \multirow{2}{*}{$\begin{array}{l}\text { Widmer et al. [14], } \\
\text { input-driven }\end{array}$} & \multirow{2}{*}{$\begin{array}{l}\text { Alonso et al. [13], } \\
\text { input-driven }\end{array}$} & \multirow{2}{*}{$\begin{array}{l}\text { Cullbrand and } \\
\text { Magnusson [12], } \\
\text { input-driven }\end{array}$} & \multirow{2}{*}{$\begin{array}{l}\text { MOE [11], } \\
\text { input-driven }\end{array}$} & \multicolumn{2}{|c|}{ MOE [10], output-driven } & \multirow{2}{*}{$\begin{array}{l}\text { Widmer et al. [14], } \\
\text { output-driven }\end{array}$} \\
\hline & & & & & b1996 & a2000 & \\
\hline $\mathrm{La}$ & 12.00 & 8.10 & 5.22 & 0.84 & & & 1.14 \\
\hline $\mathrm{Ce}$ & 0.02 & 81.00 & 0.29 & & & & 2.60 \\
\hline $\operatorname{Pr}$ & 0.07 & 30.60 & 0.81 & & & & 0.30 \\
\hline $\mathrm{Nd}$ & 2.16 & 297.00 & 43.38 & 1.31 & 2.47 & 19.11 & 2.08 \\
\hline $\mathrm{Sm}$ & 0.00 & 3.24 & 0.43 & 0.01 & 0.12 & 0.74 & 0.61 \\
\hline $\mathrm{Eu}$ & & 0.45 & $<0.01$ & & & & \\
\hline Gd & 0.05 & 0.36 & $<0.01$ & & & & 0.19 \\
\hline $\mathrm{Tb}$ & 0.01 & 0.00 & $<0.01$ & & ND & ND & 0.01 \\
\hline Dy & 0.03 & 27.45 & 0.83 & 0.17 & ND & ND & 0.10 \\
\hline Er & & NR & 0.18 & & & & \\
\hline $\mathrm{Yb}$ & & 0.00 & 0.16 & & & & \\
\hline $\mathrm{Sc}$ & & 1.13 & NR & & & & \\
\hline $\mathrm{Y}$ & 0.08 & 0.59 & 0.22 & & & & 0.58 \\
\hline Total & 14.42 & 449.91 & 51.52 & 2.33 & 2.59 & 19.85 & 7.61 \\
\hline
\end{tabular}

The blank means the metal was not considered in the study

$N R$ the metal was considered in the study but not reported in the results, $N D$ the metal was considered but was not detected by the chemical analysis

studies [10, 12-14]. Among the 13 REE presented in comparison, 12 REE were studied by Alonso et al. [13] and nine of these 12 REE were found in the largest mass in Alonso et al. [13]. Particularly, Ce, Pr and Dy were found less than $1 \mathrm{~g}$ per vehicle in other studies, while Alonso et al. [13] reported $81,30.60$ and $27.45 \mathrm{~g}$ per vehicle, respectively. In general, the results showed that the total masses of REE was higher in the studies applying input-driven approach than in the ones applying output-driven approach.

Hot spot is defined as the vehicle subsystem containing the largest mass of critical metals in sum. Hot spot is not identified by the largest mass of a single metal. However, when a single metal dominates in mass, it also influences the identification of the hot spot. This information was gathered only from the input-driven studies, because the information provided by the output-driven studies does not allow for identification of the source of the metals in the vehicles. The hot spot analysis is presented as a nested list shown in Table 4. $\mathrm{Cu}$ and $\mathrm{Mn}$ are excluded from hot spot analysis. For the hot spots of the four inputdriven studies, the top three metals ranked by mass in that subsystem are shown followed (if data allowed) by the top three parts ranked according to their contribution to the subsystems.

Each of the four studies had its own definition of subsystems and respective allocation of parts. We found that the definition of the subsystems and allocation of the parts were different in the four input-driven studies and basically done in two ways. One way is following the purpose of study. For example, Widmer et al. [14] divided the parts into six groups based on their functionality, whereas MOE [11] dismantled the cars and divided the parts into four general groups. The other way is following the automobile manufacturer's definition. Alonso et al. [13] defined 13 subsystems with the help from Ford Motor Company. Cullbrand and Magnusson [12] had 31 subsystems defined according to the "Volvo Car Cooperation notation of vehicle subsystems". Consequently, the allocation of the parts into subsystems varies from one study to another. For example, catalytic converter was listed under three different subsystems in three studies: "Engine system" [12], "Fuel and exhaust" [13] and "Functional mechanical" [11]. Due to the variations of the definition of subsystems and allocation of parts, the results are not often comparable on the level of subsystems. For example, the subsystem of "steering and breaks" is among the top three subsystems in Alonso et al. [13] while steering itself being the top subsystem by Cullbrand and Magnusson [12].

\section{Discussion}

The distribution of critical metals in passenger vehicles is a topic of high interest but one with small amounts of scattered information. The current available information we collected in the five studies is investigated by a variety of stakeholders: industries, academic institutions, and government. The studies were as well carried out with different 
Table 4 Top three vehicle subsystems and parts containing the largest mass of critical metals in sum in one conventional passenger vehicle among four input-driven studies

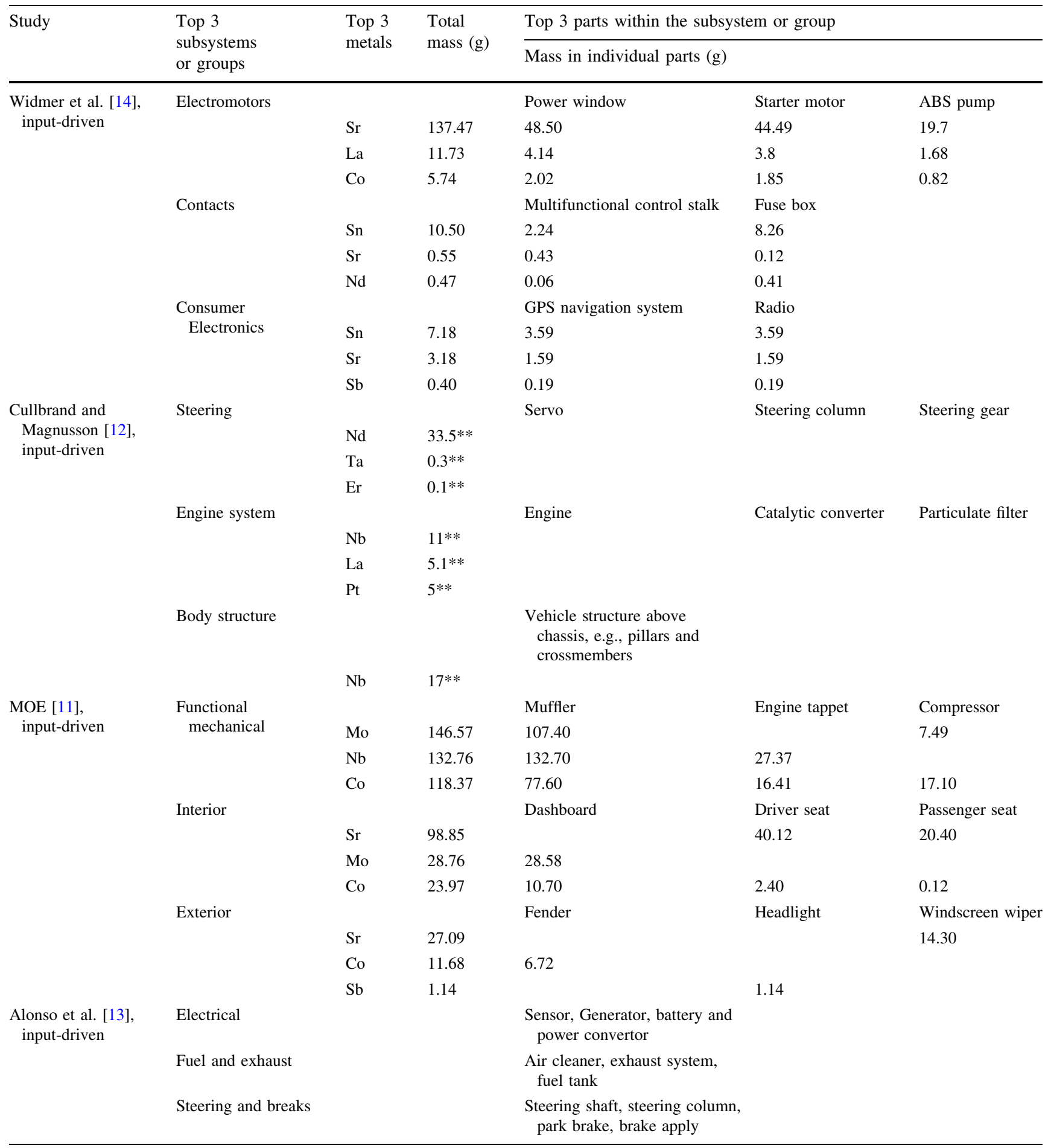

The original study does not provide numeric values

** Value was extracted from graphic presentation

purposes. The purpose, scope, and methodologies of these studies were reviewed and their results, regarding masses of critical metals in conventional passenger were consolidated. To homogenize and compare the results of such different studies, we identified two approaches: inputdriven and output-driven. 
Four issues regarding the assessment of critical metal distribution in passenger vehicles rose through our study and are discussed below: (1) metal criticality in conventional passenger vehicles, (2) number and mass of critical metals found in conventional passenger vehicles, (3) approach of quantifying the critical metals in passenger vehicles, and (4) definition of vehicle subsystems.

\section{Metal criticality in conventional passenger vehicles}

Many metals have been assessed and are considered critical by existing criticality studies [5-7, 15]. Particularly, In, Nb, $\mathrm{Pt}, \mathrm{Rh}, \mathrm{Ru}, \mathrm{Sc}, \mathrm{W}, \mathrm{Y}$, and REE (14 lanthanides) are frequently considered as critical [7]. From our results, the number of studies investigating a certain metal confirms the definition of criticality: out of the 57 elements investigated in the five studies reviewed, 25 metals were analyzed by at least three studies and all these metals are considered critical.

However, the majority of existing criticality methodologies was developed from the standpoint of national or regional economy [7]. One methodology was developed by Duclos et al. [21], considering the situation of individual corporation, General Electric (GE) as a diversified manufacturing company. As GE uses at least 70 of the first 82 elements on the periodic table, GE methodology is a more generic approach to look for corporate risks as a whole. So far, there is no public available study defining metal criticality in particular for automobile applications or for automobile industry.

Because the methodologies in the exiting criticality studies do not target automobile application, the results of metal criticality from previous studies might not reflect the actual criticality of metals used particularly in automobile. Consequently, the metals which were designated critical in the previous studies are not necessarily critical for automobile applications. Therefore, it is important to develop a methodology and assess the metal criticality for automobile applications, so that we can narrow down critical metals specifically for automobile applications.

Number and mass of critical metals found in conventional passenger vehicles

The number of metals investigated by the five studies varied from 12 in Alonso et al. [13] to 42 in MOE [10]. The five studies had different purposes and scopes to define the metals to be studied. For example, Cullbrand and Magnusson [12] chose 31 critical metals as the focus based on EU criticality study [5]. Because the numbers of critical metals studied in individual study varied, no trend regarding the number of critical metals found in passenger vehicles along the years could be observed from the data analyzed. Even though the number of studies gathered does not make for a significant sample (there might be other non-public studies, studies published in other languages, etc.,), three metals were investigated by all of them: $\mathrm{Dy}, \mathrm{Nd}$ and Sm; mainly used in magnets which are found in motors. This result potentially gives the indication that these three metals are essential for conventional passenger vehicles, particularly in the motors.

Most critical metals were found in small amounts in the vehicles. Only four of the metals $(\mathrm{Cu}, \mathrm{Mn}, \mathrm{Nd}$ and $\mathrm{Sr}$ ) were found with the median masses higher than $40 \mathrm{~g}$ per vehicle. Eight critical metals considered in at least three studies had median masses around or below $10 \mathrm{~g}$ per vehicle. The median masses of 13 metals were less than $1 \mathrm{~g}$ per vehicle. Some patterns can be found among the results of five studies. Alonso et al. [13] showed higher results for most metals compared to other studies, while Widmer et al. [14] showed smaller results in the input-driven approach than others.

However, in general, the results of most metals are scattered. There are several explanations for the scattered results. First, these five studies all differed to some extent. The differences respond to the scope of the studies and the components or parts or shredder output fractions considered for the estimations in each case. Factors such as the vehicle model, vehicle size (mass), manufacture year, specification, and the assumptions for calculation influence the final results and cause discrepancies. Second, methodological challenges can cause the variation or dispersion of the results. For example, it is challenging to select representative parts and use collected data when a hypothetical vehicle is built and analyzed. It is challenging to sample from the large and non-homogenous shredder output fractions. It is also difficult to measure the metal concentrations correctly and accurately with the interference of other metals in the samples. Nevertheless, it is difficult to identify the reasons for the dispersed results because the studies did not explicitly present the results on the level which allows us to make further interpretations. To draw conclusions of metal content in the vehicles, it requires robust data originating from more comparable studies. This involves the explicit description of the studied vehicles, by stating manufacturer, model, manufacturing year, mass and the hierarchy (including the subsystems, parts and components considered). This information would allow comparing and interpreting the results regarding content and distribution of critical metals in the studied vehicles.

Hot spot analysis was conducted with the goal to understand where the metals of interest are intensively used in conventional passenger vehicles. Hot spot is defined as the vehicle subsystem containing the largest mass of critical metals in sum. This is valuable knowledge for automakers and recyclers to prioritize targets and define 
strategies. Because each of the four studies had its own definition of subsystems and respective allocation of parts, it is difficult to compare the results among the four inputdriven studies and draw conclusions. Especially information is not presented available on the level of parts or even subsystems in some studies. With more information of metal content available on the level of subsystems and even parts, it would benefit a wide audience to think and work towards more sustainable use of metals in design, manufacturing and recycling.

Approach of quantifying the critical metal distribution in passenger vehicles

We described the input-driven approach as a way to identify metal content in components (and further on in parts and subsystems) and further extrapolate to the level of one vehicle. This approach requires substantial data input that is collected either from part supplier databases (collected data) or from chemical analysis of the components dismantled from vehicles (measured data). The outputdriven approach was described as a way to identify metal content from the output of a vehicle shredder through chemical analysis and further extrapolate to the level of one vehicle. This approach requires access to a vehicle shredder for sampling of the output fractions. Both approaches are necessary and complementary to understand the source of critical metals in the vehicles and their fate at the end of life.

The input-driven approach has an advantage over the output-driven approach in the sense that it allows the mapping of "hot spots" in the vehicle. In other words, it allows identifying where the metals of interest are intensively used. This is valuable knowledge for identification of metal dependencies, allocation of environmental impacts, identification of recycling strategies, and so forth. However, confidentiality issues arise when the input-driven study is conducted in close relation with an industry partner using collected data. In such cases, it is not possible to reveal the full set of results, the definitions of subsystems, and the parts included in the subsystems, which impedes the understanding and use of the results. Another issue with measured data is that the number of parts in a vehicle is large, so it is laborious to sample all of them or difficult to decide what parts to sample if it cannot be done for all the parts. It is also challenging to extrapolate the data from the parts to the whole vehicle. These issues add uncertainties towards the final results and must be clearly stated to ensure the credibility of the final results for further usage of the data.

The output-driven approach has an advantage over the input-driven approach in the sense that it offers a reality check for the extrapolations and assumptions taken on the input-driven approach. However, the ELV are usually dismantled or disassembled according to different standard or regulation of the region before they enter the shredders [9]. The treatment typically starts with draining the ELV from all fluids, removal of hazardous components containing mercury or explosive components (e.g., seat belt tensioners or air bags) and dismantling of certain components for reuse and recycling (e.g., catalytic converter, tires, and glass) [11]. This results in underestimation of the mass of metals in a vehicle. In addition, the shredding process causes random dispersion of the critical metals, especially for metals, which are concentrated within specific components, but are used in small amounts in the whole vehicle. The random dispersion adds uncertainties as to sampling because it is challenging to select representative samples from the large and non-homogenous fractions. At the same time, the shredding process causes reduction of the critical metal concentrations when the components containing the metals are mixed with large amount of iron or aluminum into shredder output fractions. As a result, this complicates measurement of the metal concentration because the concentrations can be too small to detect or can be affected by interferences from other metals mixed into the fractions.

\section{Definition of vehicle subsystems}

The definitions of vehicle subsystems in the studies represent a challenge: what parts make up of a subsystem? What is the difference between system and subsystem? What should be the names of the different subsystems? Some studies base their definitions on expert advice from automotive engineers, while others cluster parts according to their functionality. Ideally, the results of the studies should be presented by parts or even by components so the results can be easily compared with other results and can be further used for many purposes such as for life cycle assessment.

However, reporting by part or by component is not always possible due to confidentiality or competitiveness issues. Due to the variations among the subsystem definitions, it is not possible to tell the source of the metals and compare the distribution to other studies, when results are confidential and are only presented in an aggregated manner, either by subsystem or by car. In this case, if the definition of subsystems is not understandable or standardized, the further use of the information provided is quite limited. With standardized subsystem definitions, good estimate can be done when the information is provided by subsystems. Hence, it is imperative to create a standardized or harmonized definition of vehicle subsystems, so that the results become comparable and can be normalized for further use. We recommend defining 
subsystems according to their functions in a conventional vehicle and adjusting the hierarchy (assembly levels) to the needed resolution. Further research is required to address the definition of these functions and the optimal aggregation of parts, components and possibly further details into each subsystem.

To provide a complete set of results, more information is needed to include in the definition of vehicle subsystems besides the concentration of metals in individual parts (or even in components). The future study should state the mass of vehicle, the mass of the individual subsystems, the mass of individual parts, and the mass of individual components if the study is done on the level of components. When it is not possible for the author to release all this information, the study should at least present the definition of subsystems and allocation of parts and total mass of the vehicle if possible.

\section{Conclusions}

In this study, we presented the distribution of 25 critical metals in conventional passenger vehicle by comparing the metal distribution results between input-driven approach and output-driven approach from five studies.

In general, we identified two challenges to assess critical metal distribution in passenger vehicles: (1) methodological challenges including sampling of components and vehicle shredder outputs, chemical analysis of the metal concentrations, and extrapolation of the masses of metals in one passenger vehicle; (2) definition of subsystems and allocation of parts and components. The possible solutions to overcome these challenges are proposed below.

To overcome the methodological challenges, it is important to repeat the same method of sampling and chemical analysis to check the reproducibility of results. It is also helpful to test other methods of sampling and chemical analysis for improvement. When extrapolating the total masses of critical metals, it is necessary to consider different vehicle types. For example, the different electrification level of vehicles should be modeled by adjusting the mix of parts and components. It is important to state clearly all the assumptions and steps followed in the studies.

To overcome the challenge of comparing research results, it is necessary to develop a standardized and harmonized definition of the vehicle assembly hierarchy (subsystems, parts, and components). It would shape and direct future studies on metals' distribution in vehicles, enable the comparison of results and help to disseminate a wider knowledge and understanding of critical metals used in the vehicle fleet.
Acknowledgments We thank Michael Gasser from Empa for the help with drawing the figures and the Swiss Federal Office of the Environment (FOEN) for their financial support.

\section{References}

1. Du X, Graedel TE (2013) Uncovering the end uses of the rare earth elements. Sci Total Environ 461-462:781-784

2. Du X, Graedel TE (2011) Global rare earth in-use stocks in $\mathrm{NdFeB}$ permanent magnets. J Ind Ecol 15:836-843

3. Du X, Graedel TE (2011) Global in-use stocks of the rare earth elements: a first estimate. Environ Sci Technol 45:4096-4101

4. Yoshimura A, Daigo I, Matsuno Y (2013) Global substance flow analysis of indium. Mater Trans 54:102-109

5. European Commission (2010) Critical raw materials for the EU

6. DOE (2011) US Department of Energy Critical Materials Strategy

7. Erdmann L, Graedel TE (2011) Criticality of non-fuel minerals: a review of major approaches and analyses. Environ Sci Technol 45:7620-7630

8. Wäger P, Lang D, Wittmer D, Bleischwitz R, Hageluken C (2012) Towards a more sustainable use of scarce metals: a review of intervention options along the metals life cycle. GAIA 21:300-309

9. Sakai S, Yoshida H, Hiratsuka J, Vandecasteele C, Kohlmeyer R, Rotter V et al (2013) An international comparative study of endof-life vehicle (ELV) recycling systems. J Materl Cycles Waste Manag 16(1):1-20

10. Ministry of Environment Japan (2010) Report on 2010 Survey to Identify the Characteristics of Automotive Shredder Residue. Ministry of the Environment, Japan

11. Ministry of Environment Japan (2009) Report on FY2009 Survey to Promote Streamlining of End-of-Life Vehicle Recycling. Ministry of the Environment, Japan

12. Cullbrand K, Magnusson O (2012) The use of potentially critical materials in passenger cars. Chalmers University of Technology, Gothenburg

13. Alonso E, Wallington T, Sherman A, Everson M, Field F, Roth R et al (2012) An assessment of the rare earth element content of conventional and electric vehicles. SAE Int $J$ Mater Manuf 5:473-477

14. Widmer R, Du X, Restrepo E, Wäger P (2014) Scarce Metals in Conventional Passenger Vehicles and End-of-Life Vehicle Shredder Output (in review)

15. Commission European (2014) "Report on critical raw materials for the EU " European Commission. Belgium, Brussels, p 2014

16. Deetman S, Kleijn R, Bringezu S, Schütz H, Pauliuk S (2014) "D6.1 Indicators for critical materials," ed

17. Müller E, Hilty LM, Widmer R, Schluep M, Faulstich M (2014) Modeling metal stocks and flows-a review of dynamic material flow analysis methods. Environ Sci Technol 48(4):2102-2113

18. Mathys R, Dittmar J, Johnson CA, Krähenbühl P (2007) Antimony in Switzerland: a substance flow analysis: federal office for the environment FOEN

19. Claeys C, Simoen E (2011) Germanium-based technologies: from materials to devices. Elsevier

20. Kavlak G, Graedel TE (2013) Global anthropogenic tellurium cycles for 1940-2010. Resour Conserv Recycl 76:21-26

21. Duclos SJ, Otto JP, Konitzer DG (2010) Design in an era of constrained resources. Mech eng 132:36-40 